\title{
AN UNCLEAR SELF LEADS TO POOR MENTAL HEALTH: SELF-CONCEPT CONFUSION MEDIATES THE ASSOCIATION OF LONELINESS WITH DEPRESSION
}

\author{
STEPHANIE B. RICHMAN \\ Westminster College \\ RICHARD S. POND, JR. \\ University of North Carolina Wilmington \\ C. NATHAN DEWALL \\ University of Kentucky \\ MADOKA KUMASHIRO \\ Goldsmiths, University of London
}

ERICA B. SLOTTER

Villanova University

LAURA B. LUCHIES

Calvin College

Past research has established that loneliness is associated with both self-concept confusion and depression. The present work ties these disparate lines of research together by demonstrating that self-concept confusion mediates the relationship

\footnotetext{
The first two authors contributed equally to this work.

This research would not have been possible without funding from grants from NSF (BCS-11041118 to Nathan DeWall; BCS-719780 to Eli Finkel and BCS-0132398 to Caryl Rusbult) and Templeton Foundation (Grant 5158) to Caryl Rusbult.

Address correspondence to Stephanie B. Richman, Department of Psychology, Westminster College, New Wilmington, PA 16172 or Richard S. Pond, Jr., Department of Psychology, University of North Carolina Wilmington, Wilmington, NC, 28403; E-mail: richmasb@westminster.edu or pondr@uncw.edu.
} 
between loneliness and depression. Three studies, one cross-sectional and two longitudinal, supported this hypothesis. Moreover, the model was supported both in samples of dating and married couples and in samples of noncouples. This research contributes to a greater understanding of why people who feel socially disconnected have poor mental health. Understanding this mechanism has important implications for strategies targeting the early prevention of depression and improving mental health outcomes.

Keywords: loneliness; self-concept confusion; depression; relationships

The advice, "Know thyself," given by Plato over 2000 years ago, remains valuable today. Self-concept clarity refers to the extent to which self-knowledge is clearly defined, internally consistent, and temporally stable (Campbell et al., 1996). Knowing oneself is beneficial to mental and physical health. Not possessing a clear and consistent sense of who one is, however, is associated with a variety of negative outcomes, including depression (Bigler, Neimeyer, \& Brown, 2001; Campbell, 1990; Campbell, Assanand, \& DiPaula, 2003; Slotter, Gardner, \& Finkel, 2010). Under what circumstances are people likely to feel this sense of self-concept confusion and experience the negative outcomes associated with it? Feeling socially disconnected, as lonely people typically feel, predicts self-concept confusion (Ayduk, Gyurak, \& Luerssen, 2009; Slotter et al., 2010). Moreover, both loneliness and self-concept confusion predict depression (e.g., Bigler et al., 2001; Campbell et al., 2003; George, Blazer, Hughes, \& Fowler, 1989; Joiner, Lewinsohn, \& Seeley, 2002). Thus, research findings suggest that self-concept confusion, loneliness, and depression are linked, but research to date have yet to examine their precise relationship. The present research will unite these lines of research by examining whether self-concept confusion mediates the association between loneliness and depression.

\section{LONELINESS AND SELF-CONCEPT CONFUSION}

One way in which people come to know themselves is through their interactions with others. The self-concept is inherently social (Cooley, 1902; Mead, 1934). People create and maintain their self-concepts based on information they obtain from social environments and interactions (e.g., Cooley, 1902; Markus \& Wurf, 
1987). People perceive themselves in the way that others perceive them and this affects their self-concept (Cooley, 1902; Mead, 1934). But what happens to the selves of people who have impoverished social environments? People who are lonely-those who feel chronically socially disconnected-have relatively impoverished social environments. Lonely people have a lack of meaningful social interaction, specifically, they tend to perceive a discrepancy between their actual and desired levels of social connection (Cacioppo \& Patrick, 2008). Although lonely individuals likely have others to interact with, these interactions may not be meaningful in that they provide limited social support. The lack of meaningful social interaction results in lonely people not having others to provide them with adequate information about the self to validate and affirm their self-concept. Recent evidence supports the idea that not having someone to regularly validate the self predicts self-concept confusion. People who recently experienced a romantic breakup reported higher selfconcept confusion and emotional distress (Slotter et al., 2010). In a longitudinal study, the relationship between romantic breakup and emotional distress was mediated by self-concept confusion over time (Slotter et al., 2010). Thus, losing a social source of self-knowledge increases self-concept confusion, which, in turn, leads to emotional distress. This study gives evidence that a concept related to loneliness, a breakup, increases self-concept confusion, which leads to a concept related to depression, emotional distress. Additional research supports the idea that self-concept confusion is related to negative emotional outcomes.

\section{SELF-CONCEPT CONFUSION AND DEPRESSION}

Psychological well-being hinges on having a clear sense of who and what one is, otherwise known as self-concept clarity (Campbell et al., 2003). Self-concept confusion, which describes low levels of self-concept clarity, is associated with a variety of negative outcomes. These outcomes include impaired psychological adjustment as well as higher levels of neuroticism, anxiety, and depression (Bigler et al., 2001; Campbell, 1990; Campbell et al., 2003; Campbell et al., 1996). There is also evidence that selfconcept confusion mediates the relationships between stress and subjective well-being and between stress and depression (Chang, 
2001; Ritchie, Sedikides, Wildschut, Arndt, \& Gidron, 2010). This research suggests that self-concept confusion may also mediate the relationship between a related variable-loneliness-and depression. As of yet, however, no research has examined the role of self-concept confusion in the relationship between loneliness and depression.

\section{LONELINESS AND DEPRESSION}

Though there is no research on the mediating role of self-concept confusion in the relationship between loneliness and depression, much is known about that relationship. As early as 1967, psychologists, such as Beck, reported that feelings of loneliness were related to depression (Beck, 1967). Since then, the relationship between loneliness and depression has been substantiated in a variety of populations, including adolescents (e.g., Joiner et al., 2002; Moore \& Schultz, 1983) and college students (e.g., Ouellet \& Joshi, 1986; Rich \& Bonner, 1987; Wilbert \& Rupert, 1986). In a study of almost 2,000 adolescents, elevated loneliness predicted the onset of a major depressive episode, even controlling for initial depression (Joiner et al., 2002). Moreover, increased feelings of belongingness promoted better psychological functioning among depressed people (Hagerty, Williams, Coyne, \& Early, 1996). In a study of 150 adults diagnosed with major depressive disorder, greater social support predicted better recovery from a depressive episode (George et al., 1989). Compared to a variety of demographic and personality variables, subjective social support was the most significant predictor of recovery from depression (George et al., 1989). People who perceived they had better social support were the most likely to recover from depression. Thus, loneliness and depression are robustly related in a variety of samples, including among people who have a significant amount of contact with others, such as those in romantic relationships.

While it seems intuitive that people in romantic relationships should not be lonely, this is not always the case. Loneliness is the difference between perceived and actual social support (Cacioppo \& Patrick, 2008); thus people in romantic relationships can feel loneliness despite having at least one social connection. In fact, loneliness is prevalent in a majority of the population 
(e.g., West, Kellner, \& Moore-West, 1986) and across a variety of age groups-regardless of their relationship status (e.g., Rokach, 2000). A representative study of Swedish people between the ages of 15 and 80 showed that $40 \%$ of married people experienced loneliness sometimes or often (Tornstam, 1992). People in romantic relationships are more likely to feel lonely when they are insecurely attached (e.g., Shaver \& Hazan, 1987), have a larger discrepancy between their need to belong and satisfaction with their relationships (Mellor, Stokes, Firth, Hayashi, \& Cummins, 2008), and were generally less satisfied with their relationship and experienced more relational disappointment (Flora \& Segrin, 2000). Both single and coupled people can and do experience loneliness.

\section{THE PRESENT RESEARCH}

The goal of the present research is to connect the lines of research that link both loneliness and self-concept confusion to depression. We will do this by demonstrating that self-concept confusion mediates the link between loneliness and depression. We will examine loneliness in both single and coupled people to investigate the potentially different effects of our model in both samples. Three studies tested the hypothesis that self-concept confusion mediates the relationship between loneliness and depression. Study 1 provides an initial test of this hypothesis in a sample of coupled and single individuals. In Studies 2 and 3, we sought to replicate this pattern using longitudinal data from couples and noncouples in college and community samples. We predicted that lonelier people would experience more depressive symptoms than people who are less lonely. Moreover, we predicted that high levels of self-concept confusion would mediate the associations between loneliness and depression.

\section{STUDY 1}

In Study 1, we tested our central hypothesis that self-concept confusion mediates the relationship between loneliness and depression and examined whether this relationship differed for single people versus those in romantic relationships. We hypoth- 
esized that self-concept confusion would mediate the relationship between loneliness and depression and that these associations would remain robust when controlling for relationship status. We used several measures of loneliness and depression in this study to ensure it was the constructs themselves, rather than the specific measurements, that were causing the effect.

\section{METHOD}

Participants and Procedure. Participants were 154 students (105 women) from a large southeastern American university who completed a larger study about personality, mental health, and motivational processes for partial course credit. Participants completed the measures in groups of 8 to 15 students and were debriefed following the study. Participants were 18.93 years old on average $(S D=1.42)$. Seventy-three point four percent were Caucasian, 14.9\% African American, 4.5\% Asian, 2.6\% Hispanic, $3.9 \%$ Native American, and .6\% Other. Sixty of them were in a relationship. On average, participants who were in relationships had been in their current relationship for 14.53 months $(S D=$ 15.56).

\section{MATERIALS}

Emotional and Social Loneliness. Participants completed the 10item Emotional and Social Loneliness Scale (ESLS; Wittenberg, 1986). Participants answered five questions relating to their emotional loneliness (e.g., There is no one I have felt close to for a long time) and five questions relating to their social loneliness (e.g., Most everyone around me seems like a stranger.). The measure was examined as one total scale $(\alpha=.76)$, as well as the emotional $(\alpha=.71)$ and social $(\alpha=.79)$ loneliness subscales.

UCLA Loneliness. Participants also completed the 20-item UCLA loneliness scale (Russell, Peplau, \& Ferguson, 1978). Participants responded to 20 statements in terms of how often each was descriptive of them (e.g. There is no one I can turn to). For each statement, they selected one of four options: I often feel this way (rated as 3), I sometimes feel this way (rated as 2), I rarely feel 
this way (rated as 1), or I never feel this way (rated as 0 ). This measure demonstrated good reliability $(\alpha=.92)$.

Self-Concept Confusion. Participants completed the 12-item SelfConcept Clarity Scale (Campbell et al., 1996; e.g., In general, I have a clear sense of who I am and what I am.). Each item was measured on a scale ranging from 1 (Strongly disagree) to 5 (Strongly agree). The measure demonstrated good reliability ( $\alpha$ $=.85)$. To facilitate interpretation, items were scored such that higher scores reflected greater self-concept confusion.

CES-D Depression. Participants completed the 20-item Center for Epidemiological Studies Depression Scale (CES-D; Radloff, 1977). They answered questions about how often they felt or behaved in a variety of ways related to depression over the past week (e.g., I felt that I could not shake off the blues even with help from my family and friends). The loneliness item (i.e., I felt lonely) was removed from the scale before analyses. This measure demonstrated good reliability $(\alpha=.87)$.

Beck Depression. Participants completed the 21-item Beck Depression Inventory (BDI; Beck, Ward, Mendelson, Mock, \& Erbaugh, 1961). They answered questions about how often they feel characteristic attitudes and symptoms of depression. Each question was rated on a scale from 0 to 3 , with a rating scale specific to that question. For example, "I do not feel sad" is a 0, "I feel sad" is a 1, "I am sad all the time and I can't snap out of it" is a 2, and "I am so sad and unhappy that I can't stand it" is a 3. This measure demonstrated good reliability $(\alpha=.89)$.

\section{RESULTS AND DISCUSSION}

Our main hypothesis was that people who reported feeling lonelier would report more depression than people who reported feeling less lonely, and that this relationship would be mediated by self-concept confusion. To test our hypothesis, we used the ESLS measure of loneliness and the CESD measure of depression, and we used the bootstrapping method (Preacher \& Hayes, 2008; Shrout \& Bolger, 2002) to test for mediation (see Table 1 for model results). Finally, we employed the kappa-squared measure of effect size for mediation models to facilitate interpretation 
TABLE 1. Loneliness Predicts Depression through Self-Concept Confusion (SCC; Study 1)

\begin{tabular}{lcccccc}
\hline Model & Outcome & Parameter & $\boldsymbol{B}$ & $\boldsymbol{t}$-Value & $\boldsymbol{d f}$ & $\boldsymbol{p}$-Value \\
\hline 1 & CESD & ESLS & .42 & 6.83 & 124 & $<.001$ \\
& SCC & ESLS & 1.43 & 6.20 & 124 & $<.001$ \\
& CESD & SCC & .09 & 4.23 & 123 & $<.001$ \\
& & ESLS & .28 & 4.30 & 123 & $<.001$ \\
& BDI & ESLS & 5.74 & 5.78 & 124 & $<.001$ \\
& SCC & ESLS & 1.43 & 6.19 & 124 & $<.001$ \\
& BDI & SCC & 1.61 & 4.48 & 123 & $<.001$ \\
& ESLS & 3.44 & 3.25 & 123 & .002 \\
& BDI & UCLA & 8.25 & 7.20 & 124 & $<.001$ \\
& SCC & UCLA & 2.03 & 7.60 & 124 & $<.001$ \\
& BDI & SCC & 1.29 & 3.49 & 123 & .002 \\
& UCLA & 5.64 & 4.24 & 123 & $<.001$ \\
& CESD & UCLA & .61 & 8.90 & 124 & $<.001$ \\
& SCC & UCLA & 2.03 & 7.60 & 124 & $<.001$ \\
& CESD & SCC & .07 & 2.98 & 123 & .003 \\
& UCLA & .47 & 5.90 & 123 & $<.001$ \\
\hline
\end{tabular}

Note. CESD = Center for Epidemiological Studies Depression Scale; ESLS = Emotional Social

Loneliness Scale; SCC = Self-Concept Clarity Scale; BDI = Beck Depression Inventory; UCLA = UCLA Loneliness Scale.

of our results (Preacher \& Kelly, 2011). Kappa-squared is similar to $r^{2} X Y$ and, thus, follows Cohen's (1988) conventions for what constitutes a small (.01), medium (.09), and large (.25) effect. The indirect path through self-concept confusion was statistically significant, as indicated by finding that the $95 \%$ confidence interval (bias-corrected and accelerated) for the indirect path through this mediator did not include zero $\left(.06\right.$ to $\left..24 ; \kappa^{2}=.21\right)$. The indirect path was also significant for both the Emotional (.04 to .18; $\left.\kappa^{2}=.28\right)$ and Social (.04 to .18; $\left.\kappa^{2}=.32\right)$ Loneliness subscales. We also used the Beck Depression scale as a measure of depression. Using this dependent variable, the $95 \%$ confidence interval was significant for both the ESLS $\left(1.27\right.$ to $\left.4.53 ; \kappa^{2}=.02\right)$ and UCLA loneliness $\left(1.08\right.$ to $\left.4.65 ; \kappa^{2}=.01\right)$ scales. Finally, the indirect path was also significant for the CES-D and UCLA measure of loneliness $\left(.03\right.$ to $\left..28 ; \kappa^{2}=.15\right)$. See Table 1 for full model results.

To examine whether the mediation pattern differed as a function of relationship status, we replicated the analyses, this time controlling for relationship status and the loneliness $\times$ relation- 
ship status interaction. The indirect path through self-concept confusion remained statistically significant $\left(.04\right.$ to $\left..23 ; \kappa^{2}=.19\right)$. The indirect path was also significant for both the Emotional (.05 to $\left..18 ; \kappa^{2}=.31\right)$ and Social $\left(.04\right.$ to $\left..19 ; \kappa^{2}=.21\right)$ Loneliness subscales. Using the Beck Depression scale as the dependent variable, the 95\% confidence interval was significant for both the ESLS (.99 to $3.9 ; \kappa^{2}=.01$ ) and UCLA loneliness (.99 to 4.52; $\kappa^{2}=.01$ ) scales. Finally, the indirect path was also significant for the CES-D and UCLA measure of loneliness (.02 to $\left..29 ; \kappa^{2}=.15\right)$. See Table 2 for full model results. The results indicate that, controlling for relationship status and the interaction between relationship status and loneliness, self-concept confusion significantly mediated the relationship between loneliness and depression. Moreover, the interaction between relationship status and loneliness was not significant, indicating a similar pattern of results among those in relationships and those not in relationships. Finally, the effects held regardless of what measure of loneliness or depression was used in the analyses.

Thus, single participants and participants who were in a relationship who were lonelier reported more depression, which was due in part to their increased feelings of self-concept confusion. However, the cross-sectional designs of this study limited our ability to argue for directional relationships between loneliness, self-concept confusion, and depression. To address this limitation, Study 2 used a longitudinal design.

\section{STUDY 2}

To address concerns about directionality, we conducted a longitudinal study. This allowed us to test potential alternative models, as well as conduct more stringent statistical analyses of change over time using residualized lagged analyses. We again hypothesized that the best fitting model would show that loneliness predicted greater subsequent self-concept confusion, which in turn would predict higher levels of subsequent depression. In addition, to show that loneliness is driving the effect, rather than the amount of disharmony and conflict in a relationship, couple dyadic adjustment was included as a covariate. 
TABLE 2. Loneliness Predicts Depression through Self-Concept Confusion (SCC) Regardless of Relationship Status (Study 1)

\begin{tabular}{|c|c|c|c|c|c|c|}
\hline Model & Outcome & Parameter & B & $t$-Value & $d f$ & $p$-Value \\
\hline \multirow[t]{6}{*}{1} & CESD & ESLS & 0.46 & 7.77 & 122 & $<.001$ \\
\hline & SCC & ESLS & 1.50 & 6.38 & 122 & $<.001$ \\
\hline & CESD & SCC & 0.08 & 3.87 & 121 & $<.001$ \\
\hline & & ESLS & 0.33 & 5.17 & 121 & $<.001$ \\
\hline & & Rel. Status & 0.09 & 0.79 & 122 & .43 \\
\hline & & Interaction & 0.01 & 0.23 & 122 & .82 \\
\hline \multirow[t]{6}{*}{2} & BDI & ESLS & 6.27 & 6.42 & 122 & $<.001$ \\
\hline & SCC & ESLS & 1.50 & 4.18 & 122 & $<.001$ \\
\hline & BDI & SCC & 1.47 & 4.18 & 121 & $<.001$ \\
\hline & & ESLS & 4.06 & 3.84 & 121 & $<.001$ \\
\hline & & Rel. Status & -0.69 & -0.36 & 122 & .72 \\
\hline & & Interaction & 1.09 & 1.19 & 122 & .24 \\
\hline \multirow[t]{6}{*}{3} & BDI & UCLA & 8.17 & 7.19 & 122 & $<.001$ \\
\hline & SCC & UCLA & 2.07 & 7.67 & 122 & $<.001$ \\
\hline & BDI & SCC & 1.23 & 3.36 & 121 & .001 \\
\hline & & UCLA & 5.62 & 4.23 & 121 & $<.001$ \\
\hline & & Rel. Status & -4.41 & -1.95 & 122 & .05 \\
\hline & & Interaction & 2.54 & 2.31 & 122 & .02 \\
\hline \multirow[t]{6}{*}{4} & CESD & UCLA & 0.60 & 8.69 & 122 & $<.001$ \\
\hline & SCC & UCLA & 2.07 & 7.67 & 122 & $<.001$ \\
\hline & CESD & SCC & 0.07 & 2.96 & 121 & .004 \\
\hline & & UCLA & 0.46 & 5.67 & 121 & $<.001$ \\
\hline & & Rel. Status & -0.10 & -0.76 & 122 & .45 \\
\hline & & Interaction & 0.08 & 1.14 & 122 & .26 \\
\hline
\end{tabular}

Notes. CESD = Center for Epidemiological Studies Depression Scale; ESLS = Emotional Social Loneliness Scale; SCC = Self-Concept Clarity Scale; BDI = Beck Depression Inventory; UCLA = UCLA Loneliness Scale; Rel. Status $=$ Relationship Status; Interaction $=$ Loneliness $\times$ Relationship Status Interaction.

\section{METHOD}

Participants. Participants were 98 romantic couples who completed a 5-phase longitudinal study on relationship processes. ${ }^{1}$ Each measurement phase was separated by 6 months. Participants were recruited through advertisements and notices posted

1. At Time 1, 187 couples initially took part in the study. There were no significant differences in Time 1 loneliness between participants who completed all 5 phases and those who dropped out before Time $5: t(318)=-1.31, p>.19$. 
around the local university and community. The majority of the participants who completed the study were of white ethnicity $(86 \%)$. At Time 1 of the study, participants had an average age of 25.33 years $(S D=4.72)$. On average, participants had been romantically involved (22\% were dating, 35\% were engaged, $38 \%$ were married, and 5\% indicated "other" status) for 3.41 years $(S D=2.01)$. Participants received $\$ 80$ at Time 1, $\$ 50$ at Time 2, and $\$ 110$ at Time 5 for completing the measures.

\section{MEASURES}

Loneliness. Participants completed the loneliness item (i.e., Feeling lonely) taken from the Derogatis (1994) Psychological Adjustment Scale. Participants reported the degree to which loneliness distressed or bothered them in the past 6 months on a scale ranging from 0 (Bothered me not at all) to 8 (Bothered me extremely). ${ }^{2}$

Self-Concept Confusion. At Times 2 and 5, we used an abridged 5-item measure of Campbell et al.'s (1996) self-concept clarity scale $\left(\alpha s=.86\right.$ and .62 , respectively). ${ }^{3}$ To facilitate interpretation, items were scored such that higher scores reflected greater selfconcept confusion.

Depression. Participants completed the depression subscale of the Derogatis Psychological Adjustment Scale. Each item asked participants to report how much a variety of problems (e.g., Feelings of worthlessness) have distressed or bothered them in the last 6 months on a scale ranging from 0 (Bothered me not at all) to 8 (Bothered me extremely). The depression subscale included one item assessing loneliness (feeling lonely), which was excluded to create a 12-item measure. The measure demonstrated good reliability ( $\alpha=.88, .91$, and .87 for the three time points).

2. We used a one-item questionnaire for this study because we were concerned about attrition rate, given the length of our questionnaires and the longitudinal nature of our study. The results of Study 1 also indicated that regardless of the measure used, we found identical results.

3. At Time 2, the full 12-item measure of Campbell et al.'s (1996) self-concept clarity scale was assessed $(\alpha=.91)$. To use identical measures between Times 2 and 5 , we report on analyses using the 5 -item self-concept clarity measure. Findings using the full measure yield similar results. 
Dyadic Adjustment. To show the effects of loneliness above and beyond relationships that are not functioning well, participants completed the 30-item dyadic adjustment scale (Spanier, 1976). This measure taps components of couple functioning, such as frequency of agreement over values, conflict management, and expression of love and satisfaction. The measure demonstrated good reliability $(\alpha=.87)$. Items were scored such that higher scores reflected greater levels of dyadic adjustment.

\section{PROCEDURE}

At Time 1, couples arrived at the laboratory, provided informed consent, and completed a battery of personality and relationship measures. Six months later, they were mailed questionnaires with prepaid postage and were asked to complete and return them to us. Eighteen months later, couples returned to the laboratory to complete a final set of questionnaires. At all time points, they completed a measure of loneliness and depression. During the second and fifth time points, participants completed the selfconcept confusion measure.

\section{RESULTS AND DISCUSSION}

We predicted that people who reported feeling lonelier would also report greater depression over time, and that this relationship would be mediated by self-concept confusion. To account for the dyadic nature of the data, we used multilevel modeling procedures recommended by Kenny, Kashy and Cook (2006) by simultaneously estimating both partners' responses in couplelevel models with SPSS Mixed Modeling (SPSS 18; SPSS Inc.). ${ }^{4}$ We performed residualized lagged analyses in order to control for Time 1 levels of each relevant outcome, and coefficients were pooled across gender. The intraclass correlation coefficient (ICC)

4. Mixed modeling in SPSS uses the Satterthwaithe approximation for obtaining degrees of freedom, which is a weighted average of the between and within degrees of freedom. Therefore, the Satterthwaithe approximation results in fractional degrees of freedom. Kenny, Kashy, and Cook (2006) recommend the Satterthwaithe estimate of degrees of freedom because it takes into account the mixture of between and within parts of the estimate. 
TABLE 3. Loneliness Predicts Depression through Self-Concept Confusion Longitudinally (SCC) (Study 2)

\begin{tabular}{lccccc}
\hline Outcome Value & Parameter & $\boldsymbol{B}$ & $\boldsymbol{t}$-Value & $\boldsymbol{d f}$ & $\boldsymbol{p}$-value \\
\hline T5 Depression & T1 Loneliness & 0.08 & 1.97 & 44.62 & .05 \\
& Dyadic Adjustment & -0.007 & -0.89 & 183.96 & .38 \\
& T1 Depression & 0.51 & 7.64 & 107.27 & $<.001$ \\
T5 Loneliness & T1 Depression & 0.17 & 1.44 & 75.46 & .16 \\
& Dyadic Adjustment & -0.02 & -1.71 & 135.86 & .09 \\
T5 SCC & T1 Loneliness & 0.31 & 3.86 & 75.46 & $<.001$ \\
& T1 Loneliness & 0.14 & 3.54 & 185.57 & .001 \\
T5 Depression & Dyadic Adjustment & -0.003 & -0.34 & 165.29 & .73 \\
& T2 SCC & 0.57 & 9.06 & 183.97 & $<.001$ \\
& T2 SCC & 0.15 & 2.33 & 173.09 & .02 \\
& D1 Loneliness & 0.08 & 1.76 & 42.99 & .09 \\
& Dyadic Adjustment & -0.004 & -0.50 & 161.74 & .62 \\
\hline
\end{tabular}

Notes. SCC = Self-Concept Confusion; T1 = Time 1; T2 = Time 2; T5 = Time 5.

for depression was 0.18 , suggesting that $82 \%$ of the variability in depression was within-couples.

As expected, results provided evidence for our mediation model (see Table 3). Initial loneliness was associated with greater depression over time. However, in a test of the alternative model, initial levels of depression were not associated with loneliness over time. This finding suggests directionality in the association between loneliness and depression over time, supporting prior work demonstrating that feelings of social disconnection often precede depression (Nolan, Flynn, \& Garber, 2003). Initial loneliness was also associated with greater self-concept confusion over time. Moreover, as in the previous studies, the longitudinal association between self-concept confusion and depression was significantly positive, controlling for initial loneliness and dyadic adjustment.

Last, we tested for the significance of the mediating effect by estimating the $95 \%$ confidence interval of the indirect effect using the empirical- $M$ test. This test generates confidence intervals for the indirect effect from critical values obtained by empirically simulating a series of distributions for the product of two normal random variables (MacKinnon, Lockwood, \& Williams, 2004). Compared to traditional methods of testing for mediation, the 
empirical- $M$ test provides more power and more accurate Type-I error rates for single-level (MacKinnon et al., 2004) and multilevel (Pituch \& Stapleton, 2008; Pituch, Stapleton, \& Kang, 2006) designs. To conduct the empirical- $M$ test, we used the computer program PRODCLIN, which provided the confidence interval of the indirect effect (MacKinnon, Fritz, Williams, \& Lockwood, 2007).

As hypothesized, the indirect path through self-concept confusion was statistically significant, as indicated by a $95 \%$ confidence interval that did not include zero $\left(0.003\right.$ to $\left.0.04 ; \mathrm{K}^{2}=0.03\right)$. Therefore, the longitudinal association between loneliness and depression was mediated longitudinally by self-concept confusion. Participants who tended to feel lonely experienced higher levels of depression, which was due in part to their feelings of self-concept confusion.

Study 2 provided additional evidence that self-concept confusion mediates the relationship between loneliness and depression. Using a community sample of romantic couples that was assessed repeatedly over two years, we showed that loneliness predicted self-concept confusion over time, which mediated subsequent increases in depression. Additionally, these effects occurred above and beyond dyadic adjustment.

\section{STUDY 3}

Study 3 sought to replicate and extend the previous studies to help explain the relationship between loneliness, self-concept confusion, and depression. Specifically, using a sample of dating undergraduate couples and a large community sample of married couples, Study 3 tested whether greater self-concept confusion mediated the relationship of loneliness with depression.

\section{METHOD}

\section{Participants}

Sample A. Participants were 75 heterosexual dating couples. The majority of the participants who completed the study were 
of white ethnicity $(67 \%)$, with an average age of 20.5 years $(S D=$ $1.70)$, as of the beginning of the study. On average, participants had been with their partner 16.9 months $(S D=13.7)$. Subjects could get up to $\$ 80$ for completion of all waves.

Sample B. Participants were 120 heterosexual married couples. The majority of the participants who completed the study were of white ethnicity $(85 \%)$, with an average age of 39.7 years $(S D=$ 13.70), as of the beginning of the study. On average, participants had been with their partner for 10.87 years $(S D=12.28)$. Subjects could get up to $\$ 120$ for completion of all waves.

\section{Measures}

Loneliness. Loneliness was measured with the two lonelinessrelated items in Ryff and Keyes's (1995) Positive Relationships with Others measure. Participants indicated the extent to which they agreed with two items (i.e., "Maintaining close relationships has been difficult and frustrating for me" and "I have not experienced many warm and trusting relationships with others") on a scale ranging from 1 (Strongly disagree) to 7 (Strongly agree). Responses across items were averaged to form a composite measure of loneliness, such that higher numbers indicated greater loneliness.

Self-Concept Confusion. Self-concept confusion was measured by Campbell's (1996) self-concept clarity scale as in studies one through three. The full-length measure demonstrated good reliability $(\alpha=.89)$ and was used at the initial assessment. A single item with face validity was taken from that scale (In general, I have a clear sense of who I am and what I am) in order to assess self-concept confusion at all 6 of the follow-up assessments. Each of these single-item measures, were significantly correlated with participants' intake assessments of self-concept confusion (Pearson's $r^{\prime} s=.39-.46$, all $\left.p s<.01\right)$.

Relationship Satisfaction. Participants completed the relationship satisfaction subscale of the Investment Model Scale (Rusbult, Martz, \& Agnew, 1998; e.g., I feel satisfied with our relationship). Each item was measured on a scale ranging from 1 (Strongly disagree) to 5 (Strongly agree). The measure demonstrated good 
reliability $(\alpha=.95)$. Items were scored such that higher scores reflected greater levels of relationship satisfaction.

Depression. Depression was measured by Straus and colleagues' (1999) depression scale. Participants completed an 8-item measure in which they rated how much they agreed with several statements (e.g., I feel sad quite often) about themselves on a scale ranging from 1 (Strongly disagree) to 7 (Strongly agree). In order to achieve approximately equal error variances, the items needed rescaling at Level 1 (Raudenbush \& Bryk, 2002). Responses across items were standardized and averaged to form a composite measure of depression, such that higher numbers indicated greater depression.

\section{Procedure}

Data for the present study comes from a larger project examining psychological processes in romantic relationships. At the beginning of each study, participants arrived to the lab for an intake session at which they completed a variety of tasks, including the loneliness, self-concept confusion, relationship satisfaction, and depression items. Following this intake session, participants completed online follow-up questionnaires once a month for 6 months (Sample A; total of 7 waves) or once every four months for two years (Sample B; total of 7 waves), including the measures of loneliness, self-concept confusion, relationship satisfaction, and depression.

\section{RESULTS AND DISCUSSION}

To account for the nested structure of our data, we again used multilevel modeling procedures recommended by Kenny and colleagues (2006). For Sample A, a total of 972 responses were provided by 150 participants $(M=6.48)$. For Sample B, a total of 1,630 days of data were provided by 240 participants $(M=6.79)$.

Our initial analyses focused on the reliability of the measures for loneliness and depression. We followed procedures recommended by Nezlek (2011) for assessing scale reliability with nested data. Using a three-level unconditional model with items 
(Level 1) nested within assessments (Level 2) and assessments nested within people (Level 3), analyses showed that the two items for monthly loneliness and the eight items for monthly depression had adequate reliability (Sample A: 0.54 and 0.72, respectively; Sample B: 0.74 and 0.90, respectively). For Sample A, the intraclass correlation coefficient (ICC) for depression was 0.26 , suggesting that $74 \%$ of the variability in depression was within-person. For Sample B, the intraclass correlation coefficient (ICC) for depression was 0.37 , suggesting that $63 \%$ of the variability in depression was within-person.

Following these initial analyses, data from both Samples A and B were combined. A dummy variable for sample type was included in all formal tests of our hypotheses, as well as its interaction with loneliness, to ensure that our results were not moderated by sample type. Absence of moderation by sample would present evidence that our mediation model replicates longitudinally across student and community samples.

We predicted that people who reported feeling more lonely would also report greater depression over time and that this relationship would be mediated by self-concept confusion. We again conducted residualized lagged analyses with SPSS Mixed Modeling (SPSS 21; SPSS Inc.) by simultaneously estimating both partner's responses in couple-level models (Kenny et al., 2006) with coefficients pooled across gender.

As expected, results provided evidence for our mediation model (see Table 4). Reports of loneliness at one wave earlier ( $t$ 1 ) were associated with greater depression over time. However, in testing the alternative model, levels of depression at one wave $(t-1)$ earlier were similarly associated with greater loneliness over time. These findings suggest that loneliness and depression have a bi-directional relationship. Yet, analyses revealed that self-concept confusion served as a mediator only for our hypothesized model. Sample type did not have a moderating effect on any of the observed results.

We again tested for significance of the mediating effect by estimating the $95 \%$ confidence interval of the indirect effect using the empirical- $M$ test and PRODCLIN program (MacKinnon, et al., 2007). As hypothesized, the indirect path through self-concept confusion was statistically significant $(95 \% \mathrm{CI}=0.001$ to 
TABLE 4. Loneliness Predicts Depression through Self-Concept Confusion Longitudinally (Study 3)

\begin{tabular}{|c|c|c|c|c|c|}
\hline Outcome & Parameter & $\boldsymbol{B}$ & $t$-Value & $d f$ & $p$-Value \\
\hline \multirow[t]{5}{*}{ Depression } & Loneliness (t-1) & 0.06 & 3.39 & 99.47 & .001 \\
\hline & Satisfaction (t-1) & -0.03 & -3.45 & 1619.12 & .001 \\
\hline & Sample & -0.07 & -2.70 & 870.32 & .007 \\
\hline & Sample $\times$ Loneliness & -0.008 & -0.33 & 126.89 & .74 \\
\hline & Depression (t-1) & 0.52 & 26.56 & 173.24 & $<.0001$ \\
\hline \multirow[t]{5}{*}{ Loneliness } & Depression (t-1) & 0.06 & 2.79 & 56.84 & .007 \\
\hline & Satisfaction (t-1) & -0.04 & -3.16 & 1044.62 & .002 \\
\hline & Sample & 0.008 & 0.27 & 748.96 & .79 \\
\hline & Sample $\times$ Depression & 0.04 & 1.17 & 100.02 & .25 \\
\hline & Loneliness (t-1) & 0.51 & 22.73 & 186.32 & $<.0001$ \\
\hline \multirow[t]{5}{*}{ SCC } & Loneliness (t-1) & 0.09 & 3.14 & 1787.90 & .002 \\
\hline & Satisfaction (t-1) & -0.03 & -1.84 & 1498.88 & .07 \\
\hline & Sample & -0.09 & -1.87 & 943.87 & .06 \\
\hline & Sample $\times$ Loneliness & 0.01 & 0.24 & 1779.25 & .81 \\
\hline & $\operatorname{SCC}(\mathrm{t}-1)$ & 0.61 & 31.50 & 1792.24 & $<.0001$ \\
\hline \multirow[t]{5}{*}{ SCC } & Depression (t-1) & 0.26 & 7.84 & 571.52 & $<.0001$ \\
\hline & Satisfaction (t-1) & 0.009 & 0.48 & 236.63 & .63 \\
\hline & Sample & -0.06 & -1.16 & 57.80 & .25 \\
\hline & Sample $\times$ Loneliness & 0.02 & 0.72 & 181.42 & .47 \\
\hline & Depression (t-1) & 0.55 & 25.88 & 1479.30 & $<.0001$ \\
\hline \multirow[t]{6}{*}{ Depression } & $\operatorname{SCC}(\mathrm{t}-1)$ & 0.05 & 3.96 & 1679.05 & $<.0001$ \\
\hline & Loneliness (t-1) & 0.03 & 1.70 & 192.70 & .09 \\
\hline & Satisfaction (t-1) & -0.02 & -2.66 & 1359.73 & .008 \\
\hline & Sample & -0.05 & -2.09 & 810.33 & .04 \\
\hline & Sample $\times$ Loneliness & 0.02 & 0.72 & 181.42 & .47 \\
\hline & Depression (t-1) & 0.55 & 35.88 & 1479.30 & $<.0001$ \\
\hline \multirow[t]{6}{*}{ Loneliness } & $\operatorname{SCC}(\mathrm{t}-1)$ & 0.002 & 0.16 & 1366.45 & .87 \\
\hline & Depression (t-1) & 0.05 & 2.11 & 937.69 & .04 \\
\hline & Satisfaction (t-1) & -0.04 & -3.42 & 345.91 & .001 \\
\hline & Sample & 0.003 & 0.09 & 107.65 & .93 \\
\hline & Sample $\times$ Depression & 0.04 & 1.18 & 461.59 & .24 \\
\hline & Loneliness (t-1) & 0.51 & 22.41 & 162.11 & $<.0001$ \\
\hline
\end{tabular}

Notes. SCC = Self-Concept Clarity Scale; Satisfaction = Relationship Satisfaction; $\mathrm{t}-1$ = one wave earlier. 
$\left.0.008 ; \kappa^{2}=.006\right)$. However, the indirect path through self-concept confusion for the alternative model was not statistically significant $\left(95 \% \mathrm{CI}=-0.007\right.$ to $\left.0.009 ; \kappa^{2}=.001\right)$. Hence, the results support a longitudinal model in the direction of loneliness predicting greater depression over time through self-concept confusion, but not the reverse model.

The results of Study 3 replicate the previous two studies, showing that feelings of loneliness relate to a less clear sense of self that is associated with greater levels of depression. Moreover, the results of Study 3 replicate the pattern of mediational results observed over time across both student and community samples. These results suggest that feeling lonely relates to a less clear self-concept, which predicts greater levels of depression.

\section{GENERAL DISCUSSION}

Knowing oneself has important implications for one's mental health. Self-concept confusion is related to decreased psychological adjustment and increased neuroticism, anxiety, and depression (Bigler et al., 2001; Campbell, 1990; Campbell et al., 2003; Campbell et al., 1996). Additional research suggests that selfconcept confusion plays a mediational role in the relationship between romantic breakup and emotional distress (Slotter et al., 2010), as well as between stress and subjective well-being and stress and depression (Chang, 2001; Ritchie et al., 2010). While previous literature has addressed the important role of self-concept confusion for many variables related to mental health, it has not addressed whether it plays a role in the robust relationship between loneliness and depression. The current investigation sought to fill this gap in the literature by demonstrating that loneliness hampers the organization and stability of the self-concept, which may have direct implications for depression.

Self-concept confusion may partially derive from a lack of interaction partners who regularly validate the self. Even people in romantic relationships may not be shielded from this effect, given that they may not be getting their desired amount of social connection from their partner. Loneliness, the discrepancy 
between desired and actual social connection, is prevalent in a majority of the population, regardless of their relationship status (e.g., Rokach, 2000). Given this knowledge about loneliness and self-concept confusion as well as prior work suggesting a relationship between self-concept confusion and depression (e.g., Bigler et al., 2001; Campbell, 1990; Campbell et al., 1996), we predicted that self-concept confusion would mediate the relationship between loneliness and depression. All three studies showed consistent support for our hypotheses. In each study, self-concept confusion mediated the relationship between loneliness and depression. Importantly, depression did not seem to predict loneliness at a later time point. Finally, the relationship held for both single and coupled participants.

While previous research demonstrates associations between these variables separately, the present research is the first to tie this research together. This consistent pattern of relationships among these constructs was found with separate samples of people at different life stages, with different relationship statuses, using different measures of the key constructs. It is a considerable strength of this paper that we are able to generalize our findings to a broader population. The fact that many participants were in romantic relationships also suggests that this pattern comes from being lonely, independent of actual social isolation; another novel contribution of the present research. In addition, by controlling for dyadic adjustment, the findings further show that these effects are driven by perception of loneliness rather than being in a dissatisfying or poorly functioning relationship.

\section{LIMITATIONS AND FUTURE DIRECTIONS}

Although the current findings consistently supported our hypotheses, there were several limitations that may serve as avenues for future research. First, we explored only the mechanism behind the relationship between loneliness and depression. It is possible that this mechanism may relate to other negative health outcomes, including people's physical health. For example, depression is strongly associated with chronic physical conditions, such as diabetes, arthritis, multiple sclerosis, and congestive heart failure (Egede, 2007; Lin et al., 2008; Patten et al., 2005; Pat- 
ten, Beck, Williams, Barbui, \& Metz, 2003; Prince et al., 2007) and with nonspecific syndromes like obesity (Scott, McGee, Wells, \& Oakley Browne, 2008). Additionally, both social disconnection (e.g., Olsen, Olsen, Gunner-Svensson, \& Waldstrøm, 1991; Shiovitz-Ezra \& Ayalon, 2010) and depression (see Wulsin, Wulsin, Vaillant, \& Wells, 1999 for a review) relate to increased mortality rates. Self-concept confusion may also help explain the relationships between loneliness, depression, and decreased physical health or increased mortality in romantic couples. Future research may examine these possibilities.

Another limitation is that we only focused on one type of social exclusion experience, namely generalized loneliness. Rejection, feelings of belongingness, and perceived social support also all significantly predict depression (George et al., 1989; Hagerty \& Patusky, 1995; Hagerty et al., 1996). Previous research demonstrates that self-concept confusion also mediates the relationship between romantic breakup, another type of social disconnection, and feelings of emotional distress (Slotter et al., 2010). Our research may thus generalize to social disconnection as a whole rather than only to loneliness. It is also possible that negative social experiences, such as romantic breakup, may also lead to increased feelings of loneliness. Future research may want to investigate this claim.

Next, future research could also explore whether it is the evaluative (positivity of beliefs about the self, e.g., self-esteem) or structural (contents of the self-concept, e.g., roles, values) changes of the self-concept following social disconnection that are driving its effects on physical and mental health. It may be one or the other of these components alone that is driving the effects we find. We know that low levels of self-esteem are associated with a variety of negative consequences, including higher levels of loneliness and depression (Creemers, Scholte, Engels, Prinstean, \& Weirs, 2012; Hermann \& Betz, 2006; Olmstead, Guy, O'Mally, \& Bentler, 1991; Oullet \& Joshi, 1986). These findings suggest that it may be the evaluative component of the self that is being most affected by social disconnection.

Finally, self-concept confusion may help explain impairments that frequently accompany feelings of social exclusion. When people feel socially excluded, their self-concept confusion may 
undermine their personal standards that normally motivate people to regulate their impulses (Baumeister et al., 2005; Oaten, Williams, Jones, \& Zadro, 2008), to avoid selfish and self-defeating behaviors (Twenge et al., 2002; Van Beest \& Williams, 2006), and to override their aggressive urges (DeWall, Twenge, Gitter, \& Baumeister, 2009; Warburton, Williams, \& Cairns, 2006; Wesselman, Butler, Williams, \& Pickett, 2010). Self-concept confusion may also have implications for understanding the relationships between social exclusion and negative behavioral outcomes such as those listed above. Understanding these relationships can help researchers devise methods for lonely people and people high in self-concept confusion to avoid these negative mental health outcomes.

\section{CONCLUDING REMARKS}

Having an unclear, disorganized, and unstable self-structure is extremely disadvantageous. People who do not know themselves very well are less mentally healthy compared to people who do know themselves well. Factors that contribute to selfconcept confusion have broad implications for psychological well-being. Loneliness is one such factor. The perception of having weak social support has deleterious consequences on a person's mental health. Even people in satisfying relationships can feel lonely. Loneliness disrupts the clarity and structure of the self, which, in turn, disrupts people's mental health.

\section{REFERENCES}

Ayduk, O., Gyurak, A., \& Luerssen, A. (2009). Rejection sensitivity moderates the impact of rejection on self-concept clarity. Personality and Social Psychology Bulletin, 35, 1467-1478.

Baumeister, R. F., DeWall, C. N., Ciarocco, N. J., \& Twenge, J. M. (2005). Social exclusion impairs self-regulation. Journal of Personality and Social Psychology, $88(4), 589-604$.

Beck, A. T. (1967). Depression: Clinical experimental and theoretical aspects. New York: Harper \& Row.

Beck, A. T., Ward, C. H., Mendelson, M., Mock, J., \& Erbaugh, J. (1961). An inventory for measuring depression. Archives of General Psychiatry, 4, 561-571. 
Bigler, M., Neimeyer, G. J., \& Brown, E. (2001). The divided self revisited: Effects of self-concept clarity and self-concept differentiation on psychological adjustment. Journal of Social and Clinical Psychology, 20, 396-315.

Cacioppo, J. T., \& Patrick, W. (2008). Loneliness: Human nature and the need for social connection. New York: Norton.

Campbell, J. D. (1990). Self-esteem and clarity of the self-concept. Journal of Personality and Social Psychology, 59, 538-549.

Campbell, J. D., Assanand, S., \& DiPaula, A. (2003). The structure of the self-concept and its relation to psychological adjustment. Journal of Personality, 71, $115-140$.

Campbell, J. D., Trapnell, P. D., Heine, S. J., Katz, I. M., Lavallee, L. F., \& Lehmann, D. R. (1996). Self-concept clarity: Measurement, personality correlates, and cultural boundaries. Journal of Personality and Social Psychology, 70, 141-156.

Chang, E. C. (2001). Life stress and depressed mood among adolescents: Examining a cognitive-affective mediation model. Journal of Social and Clinical Psychology, 20, 416-429.

Cohen, J. (1988). Statistical power analysis for the behavioral sciences (2nd ed.). Hillsdale, NJ: Lawrence Erlbaum Associates.

Cooley, C. H. (1902). Human nature and the social order. New York: Charles Scribner's Sons.

Creemers, D.H.M., Scholte, R.H.J., Engels, R.C.M.E., Prinstean, M. J., \& Weirs, R.W.S. (2012). Implicit and explicit self-esteem as concurrent predictors of suicidal ideation, depressive symptoms, and loneliness. Journal of Behavior Therapy and Experimental Psychiatry, 43, 638-646.

Derogatis, L. R. (1994). SCL-90-R: Symptom Checklist-90-R: Administration, scoring, and procedures manual (3rd ed.). Minneapolis, MN: National Computer Systems, Inc.

DeWall, C. N., Twenge, J. M., Gitter, S. A., \& Baumeister, R. F. (2009). It's the thought that counts: The role of hostile cognition in shaping aggressive responses to social exclusion. Journal of Personality and Social Psychology, 96, 45-59.

Egede, L. E. (2007). Major depression in individuals with chronic medical disorders: Prevalence, correlates and association with health resource utilization, lost productivity and functional disability. General Hospital Psychiatry, 29, 209-216.

Flora, J., \& Segrin, C. (2000). Relationship development in dating couples: Implications for relational satisfactiona and loneliness. Journal of Social and Personal Relationships, 17, 811-825.

George, L. K., Blazer, D. G., Hughes, D. C., \& Fowler, N. (1989). Social support and the outcome of major depression. British Journal of Psychiatry, 154, 478-485.

Hagerty, B.M.K., \& Patusky, K. L. (1995). Developing a measure of sense of belonging. Nursing Research, 44, 9-13.

Hagerty, B.M.K., Williams, R. A., Coyne, J. C., \& Early, M. R. (1996). Sense of belonging and indicators of social and psychological functioning. Archives of Psychiatric Nursing, 10, 235-244.

Hermann, K. S., \& Betz, N. E. (2006). Models of the relationships of instrumentality and expressiveness, social self-efficacy, and self-esteem to depressive symptoms in college students. Journal of Social and Clinical Psychology, 25, 1086-1106. 
Joiner, T. E., Lewinsohn, P. M., \& Seeley, J. R. (2002). The core of loneliness: Lack of pleasurable engagement-more so than painful disconnection-predicts social impairment, depression onset, and recovery from depressive disorders among adolescents. Journal of Personality Assessment, 79, 472-491.

Kenny, D. A., Kashy, D. A., \& Cook, W. L. (2006). Dyadic data analysis. New York: Guilford.

Lin, E. H., Korff, M. V., Alonso, J., Angermeyer, M. C., Anthony, J., . . \& \& Williams, D. (2008). Mental disorders among persons with diabetes-results from the World Mental Health Surveys. Journal of Psychosomatic Research, 65, 571-580.

MacKinnon, D. P., Fritz, M. S., Williams, J., \& Lockwood, C. M. (2007). Distribution of the product confidence limits for the indirect effect: Program PRODCLIN. Behavior Research Methods, 39, 384-389.

MacKinnon, D. P., Lockwood, C. M., \& Williams, J. (2004). Confidence limits for the indirect effect: Distribution of the product and resampling methods. Multivariate Behavioral Research, 39, 99-128.

Markus, H., \& Wurf, E. (1987). The dynamic self-concept: A social psychological perspective. Annual Review of Psychology, 38, 299-337.

Mead, G. H. (1934). Mind, self, and society from the standpoint of a social behaviorist. University of Chicago Press: Chicago.

Mellor, D., Stokes, M., Firth, L., Hayashi, Y., \& Cummins, R. (2008). Need for belonging, relationship satisfaction, loneliness, and life satisfaction. Personality and Individual Differences, 45, 213-218.

Moore, D., \& Schultz, N. R. (1983). Loneliness at adolescence: Correlates, attributions, and coping. Journal of Youth and Adolescence, 12, 95-100.

Nezlek, J. B. (2011). Multilevel modeling for social and personality psychology. Thousand Oaks, CA: Sage.

Nolan, S. A., Flynn, C., \& Garber, J. (2003). Prospective relations between and rejection in young adolescents. Journal of Personality and Social Psychology, 85, 745-755.

Oaten, M., Williams, K. D., Jones, A., \& Zadro, L. (2008). The effects of ostracism on self-regulation in the socially anxious. Journal of Social and Clinical Psychology, $27,471-504$.

Olmstead, R. E., Guy, S. M., O'Mally, P. M., \& Bentler, P. M. (1991). Longitudinal assessment of the relationship between self-esteem, loneliness, and substance use. Journal of Social Behavior and Personality, 6, 749-770.

Olsen, R. B., Olsen, J., Gunner-Svensson, F., \& Waldstrøm, B. (1991). Social networks and longevity. A 14 year follow-up study among elderly in Denmark. Social Science \& Medicine, 33, 1189-1196.

Ouellet, R., \& Joshi, P. (1986). Loneliness in relation to depression and self-esteem. Psychological Report, 58, 821-822.

Patten, S. B., Beck, C. A., Kassam, A., Williams, J. V., Barbui, C., \& Metz, L. M. (2005). Long-term medical conditions and major depression: Strength of association for specific conditions in the general population. Canadian Journal of Psychiatry, 50, 195-202.

Patten, S. B., Beck, C. A., Williams, J. V., Barbui, C., \& Metz, L. M. (2003). Major depression in multiple sclerosis: A population-based perspective. Neurology, 61, 1524-1527. 
Pituch, K. A., \& Stapleton, L. M. (2008). The performance of methods to test upperlevel mediation in the presence of nonnormal data. Multivariate Behavioral Research, 43, 237-267.

Pituch, K. A., Stapleton, L. M., \& Kang, J. Y. (2006). A comparison of single sample and bootstrap methods to assess mediation in cluster randomized trials. Multivariate Behavioral Research, 41, 367-400.

Preacher, K. J., \& Hayes, A. F. (2008). Asymptotic and resampling strategies for assessing and comparing indirect effects in multiple mediator models. Behavior Research Methods, 40, 879-891.

Preacher, K. J., \& Kelley, K. (2011). Effect size measures for mediation models: Quantitative strategies for communicating indirect effects. Psychological Methods, 16, 93-115.

Prince, M., Patel, V., Saxena, S., Maj, M., Maselko, J., Phillips, M. R., \& Rahman, A. (2007). No health without mental health. Lancet, 370, 859-877.

Radloff, L. S. (1977). The CES-D Scale: A self-report depression scale for research in the general population. Applied Psychological Measurement, 1, 385-401. doi:10.1177/014662167700100306

Raudenbush, S. W., \& Bryk, A. S. (2002). Hierarchical linear models: Applications and data analysis methods (2nd ed.). Thousand Oaks, CA: Sage.

Rich, A., \& Bonner, R. (1987). Interpersonal moderators of depression among college students. Journal of College Student Personnel, 28, 337-342.

Ritchie, T. D., Sedikides, C., Wildschut, T., Arndt, J., \& Gidron, Y. (2010). Self-concept clarity mediates the relation between stress and subjective well-being. Self and Identity, 10, 493-508.

Rokach, A. (2000). Loneliness and the life cycle. Psychological Reports, 86, 629-642.

Rusbult, C. E., Martz, J. M., \& Agnew, C. R. (1998). The Investment Model Scale: Measuring commitment level, satisfaction level, quality of alternatives, and investment size. Personal Relationships, 5, 357-391.

Russell, D., Peplau, L. A., \& Ferguson, M. L. (1978). Developing a measure of loneliness. Journal of Personality Assessment, 42, 290-294.

Ryff, C. D., \& Keyes, C.L.M. (1995). The structure of psychological well-being revisited. Journal of Personality and Social Psychology, 69, 719-727.

Scott, K. M., McGee, M. A., Wells, J. E., \& Oakley Browne, M. A. (2008). Obesity and mental disorders in the adult general population. Journal of Psychosomatic Research, 64, 97-105.

Shaver, P., \& Hazan, C. (1987). Being lonely and falling in love: Perspectives from attachment theory. Journal of Social Behavior and Personality, 2, 105-124.

Shiovitz-Ezra, S., \& Ayalon, L. (2010). Situational versus chronic loneliness as risk factors for all-cause mortality. International Psychogeriatrics, 22, 455-463.

Shrout, P. E., \& Bolger, N. (2002). Mediation in experimental and nonexperimental studies: New procedures and recommendations. Psychological Methods, 7, 422-445.

Slotter, E. B., Gardner, W. L., \& Finkel, E. J. (2010). Who am I without you? The influence of romantic breakup on the self-concept. Personality and Social Psychology Bulletin, 36, 147-160.

Spanier, G. B. (1976). Measuring dyadic adjustment: New scales for assessing the quality of marriage and similar dyads. Journal of Marriage and the Family, 38, $15-28$. 
Straus, M. A., Hamby, S. L., Boney-McCoy, S., \& Sugarman, D. (1999). The Personal and Relationships Profile (PRP). Durham: University of New Hampshire, Family Research Laboratory. Available: http:/ / pubpages.unh.edu/ mas2.

Tornstam, L. (1992). Loneliness in marriage. Journal of Social and Personal Relationships, 9, 197-217.

Twenge, J.M., Cantanese, K.R., \& Baumeister, R. F. (2002). Social exclusion causes self-defeating behavior. Journal of Personality and Social Psychology, 83(3), 605-615.

Van Beest, I., \& Williams, K. D. (2006). When inclusion costs and ostracism pays, ostracism still hurts. Journal of Personality and Social Psychology, 91, 918-928.

Warburton, W. A., Williams, K. D., \& Cairns, D. R. (2006). When ostracism leads to aggression: The moderating effects of control deprivation. Journal of Experimental Social Psychology, 42, 213-220.

Wesselman, E. D., Butler, F. A., Williams, K. D., \& Pickett, C. L. (2010). Adding injury to insult: Unexpected rejection leads to more aggressive responses. Aggressive Behavior, 36, 232-237.

West, D. A., Kellner, R., \& Moore-West, M. (1986). The effects of loneliness: A review of the literature. Comprehensive Psychiatry, 27, 351-363.

Wilbert, J. R., \& Rupert, P. A. (1986). Dysfunctional attitudes, loneliness, and depression in college students. Cognitive Therapy and Research, 10, 71-77.

Wittenberg, M. T. (1986). Emotional and social loneliness: An examination of social skills, attributions, sex role and object relations perspectives. Unpublished doctoral dissertation, University of Rochester, Rochester, New York.

Wulsin, L. R., Wulsin, M. D., Vaillant, M. D., \& Wells, V. E. (1999). A systematic review of the mortality of depression. Psychosomatic Medicine, 61, 6-18. 
Copyright of Journal of Social \& Clinical Psychology is the property of Guilford Publications Inc. and its content may not be copied or emailed to multiple sites or posted to a listserv without the copyright holder's express written permission. However, users may print, download, or email articles for individual use. 